\title{
Knowledge Attitude and Practice Towards Premarital Sex and HIVIAIDS among Mizan-Tepi University Students, South West Ethiopia
}

\author{
Zemenu Mengistie ${ }^{1}$, Endalamaw Wolie ${ }^{1}$, Enawgaw Abawa ${ }^{1}$, Endris Ebre ${ }^{1}$, Addis Adera ${ }^{2}$ \\ ${ }^{1}$ Department of Medical Microbiology, MizanTepi University, MizanTepi, Ethiopia \\ ${ }^{2}$ Department of Nursing, Faculty of Health Sciences, Woldia University, Woldia, Ethiopia
}

Email address:

zemenumengistie@yahoo.com (Z. Mengistie), addisaderagebru@yahoo.com (G. A. Adera)

\section{To cite this article:}

Zemenu Mengistie, Endalamaw Wolie, Enawgaw Abawa, Endris Ebre, Addis Adera. Knowledge Attitude and Practice Towards Premarital Sex and HIV/AIDS among Mizan-Tepi University Students, South West Ethiopia. Science Journal of Public Health .

Vol. 3, No. 4, 2015, pp. 592-599. doi: 10.11648/j.sjph.20150304.30

\begin{abstract}
Background: Pre-marital sex is any sexual activities with an opposite sex partners or a same sex before he/she has started a marriage life. The term is usually used to refer the inter course before the legal age of marriage. In the course of experimentation, adolescents often in counter high risk situation, as contracting STD /HIV/AIDS and often exposed to un intended pregnancy and illicit abortions. Objective: This study was conducted to assess knowledge, attitude and practice towards premarital sex and HIV/AIDS among students who are attending in MizanTepi University. Methods: A cross sectional study was conducted from April 08-September, 08, 2014- in MTU, Mizan campus regular students. Stratified sampling technique were used after making strata based on Collage and sex proportion. This study using systemic random sampling. Data were collected by three Public Health interns, using self-administrated questionnaires. Students from each Collage were being explained about the objective and confidentiality of the study while distributing and collecting the questionnaires. Results: A total of 372 participants, 254(68\%) were males and 118(32\%) were females. All of the students know what cause HIV/AIDS; majority of them knew major transmission routes. Sexual transmission mentioned as a major routes transmission in our study by $281(75.5 \%)$ of students but knowledge was translated into practice as 133(35.6\%) approved premarital sex and practiced it. Conclusion and Recommendation: The study participants have good knowledge of HIV/AIDS related to its cause, routes of transmission and also about preventive mechanism by this knowledge was not practiced. The study participants were citing religion as reason for not having premarital sex and this should include in their day to day teachings. The HIV/AIDS agenda should an agenda for everyone and families should discuss with the adolescents and adults.
\end{abstract}

Keywords: Knowledge, Attitude, Practice, Premarital Sex, HIV/AIDS

\section{Introduction}

Pre-marital sex is any sexual activities with an opposite sex partners or a same sex before he/she has started a marriage life. It's characterized as being unanticipated, unpredictable, inconsistence with values and personality uncontrollable and becoming the common feature of adolescent (1).Most age groups that started pre-marital sex are adolescent and young people. There are 1.2 billion adolescents and 1.7 billon young people in the world today of which $85 \%$ of them live in developing countries making nearly $30 \%$ of their population. Mostly adolescent age is a time to experiment with sex. In the course of experimentation, adolescents often in counter high risk situation, as contracting STD /HIV/AIDS and often exposed to un intended pregnancy and illicit abortions. For some portion the youth, adolescent is characterized by recklessness risk seeking, sexual and drug experimentation and lower perception of vulnerability to adverse effect of above risk behaviors (2).Premarital sex and unprotected sexual practices are the major health and life threatening problem school youths making them vulnerable to STIs, HIV/AIDS, unwanted pregnancy, abortion and its complication and dropout of their education. Unsafe sex is a major threat to the health and survival of millions of adolescents each year one in 20 adolescents contracts on STIs including HIV. Every day over 700 young people aged 10-24 become infected with HIV/AIDS (3).Globally the number of people living with 
HIV [PLWH] continues to grow as does the number of deaths from HIV/AIDS. According to UNAIDS repot a total of 33.2 million people were living with HIV in 2007. This figure includes the estimated 2.1 million adults and 420,000 children who were newly deaths as a result of HIV in 2007. There were 21 million deaths as result of HIV/AIDS in the year 2007 (4).In Ethiopia the adult prevalence of HIV is estimated to be $2.4 \%$ in 2010 . The prevalence among urban and rural population of during the same period is estimated it $7.7 \%$ and $0.9 \%$ respectively. The total number of PLWH in the same period estimated to be 1,216,908 [41\%males and 59\% females adult and 79,871[6.65 are children which are $<15$ years children. The number of new adult HIV infection for 2010 is estimated to be 137,494 adults and 141,093 new pediatric infections because of vertical transmission. The number of deaths due to AIDS for the same period is estimated to be 44,751 for adults and 9,284 among children $<15$ years. Reports show the incidence of HIV/AIDS among unmarried is mode of transmission, which is not translated into appreciable behavior modification. Premarriage unsafe sex is not only a high risk factor to HIV/AIDS but also STD/STI, unwanted pregnancy and subsequent dropout from school, illegal abortion and its complication, social and psychological transmit (5).To assess knowledge attitude and practice towards premarital sex and HIV/AIDS among Mizan-Tepi University, Mizan campus regular students, in Bench Maji zone south west Ethiopia, 2014.

\section{Methods and Materials}

\subsection{Study Area and Period}

The study was conducted in Mizan-Tepi University Mizan campus that is found in South West Ethiopia $565 \mathrm{kms}$ away from Addis Ababa. Its climate condition is Weynadega and has a total number of 6174 regular students in both Mizan campus and Tepi campus. From this, 2031 are females and 4143 are male's students. Among the total 882 females and 1909 males are our study populations. The study was conducted from June 15- 30/12/2006 E.C in Mizan campus.

\subsection{Study Design}

A cross sectional study was conducted.

\subsection{Study population}

The source of population was all Mizan- Tepi University, Mizan campus regular students.

Sampled Mizan-Tepi University, Mizan campus regular students. Using four collages (Health Science, Business and Economics, Social Science and Humanity and Agricultural and Natural Resource students) those in study population. Students who were absent during data collection period and not voluntary to participate.

Students who were attending weekend and summer program

\subsection{Sample Size}

To determined the sample size the level of confidence taken was $95 \%$ ( with tabular value of 1.96 ) and 5\% margin of error and proportion $(\mathrm{P}=50 \%)$ total number of students ( $\mathrm{N}=2791$ )

$$
\text { i.eni }=\left[(z o / z)^{2} p(1-p] / d^{2}(14) .\right.
$$

Where ni= minimum sample size

$\mathrm{p}=$ estimated of prevalence rate for knowledge, attitude and practice of students towards premarital sex and HIV/AIDS

$\mathrm{zo} / \mathrm{z}=$ standard normal variable at $95 \%$ confidence level $\left(95 \%=1.96\right.$ from table) $\left.\mathrm{Ni}=\left[(1.96)^{2}(0.5)(1-0.5)\right] / 0.05\right)$ ${ }^{2}=384$

$\mathrm{d}=$ margin of sample error tolerated $=0.05$

Since the total population is $<10,000$ the final sample size will by correlation formula i.e. to get the maximum sample size;

$$
\begin{gathered}
\mathrm{Nf}=\text { in } /(1+\mathrm{ni} / \mathrm{N}) \\
\mathrm{Nf}=384 /(1+384 / 2791)=338
\end{gathered}
$$

Where $\mathrm{ni}=$ minimum sample size

$\mathrm{Nf}=$ maximum sample size

$\mathrm{N}=$ total population

- Non response rate was be assumed $10 \%$ refusal to participate on the study

\section{Non response rate $=\mathrm{NfX} 10 \%$}

$$
338 \times 10 \%=33.8 \sim 34
$$

The final sample size including non-response rate was; $338+34=372$

The sample size from each collage and sex drawn as follow;

$=$ number of students in each collage $\mathrm{X}$ sample size (Nf)/total number of source of population.

- For Health Science collage $=642 X 372 / 2791=86$ respondents was selected.

- For Business and Economics collage $=501 \times 372 / 2791=67$ respondents was selected.

- For Agricultural and Natural resource collage $=605 X 372 / 2791=80$ respondents was selected.

- For Social Science and Humanity collage $=1041 \times 372 / 2791=139$ respondents was selected.

Sample size by sex:-

- Males $=1909 X 372 / 2791=254$ respondents were elected

- Female $=882 \times 372 / 2791=118$ respondents were selected

Selection of students from each collage was done through systemic random sampling i.e. $=$ Number of students $/$ sample size

- For Health Science; $642 / 86=7.46$ i.e. every 7 students were selected from the list of the students in Health collage.

- For Business and Economics; 501/67=7.4 i.e. every 7 students were be selected in Business and Economics 
collage.

- For Agricultural and Natural Resource collage; $605 / 80=7.56$ i.e. 8 students were selected from the list of the students in Agricultural and Natural Resource collage.

- For Social Science and Humanity collage; $1043 / 139=7.53$ i.e. every 8 students were be selected from the list students in Social and Humanity collage.

\subsection{Sampling Techniques and Procedure}

Stratified sampling technique were used after making strata based on collage and sex, from each strata students according to the sample size were collected by systemic random sampling.

\subsection{Instrument and Measurement}

Pretested and structured self-administered questionnaire was used. Translation of instrument is made from English language to local Oromifa Language and back to English language by different experts who are familiar on the field of area and blind to the original version of the questionnaire (English version) in order to facilitate responses to underline questions and keep the original meaning of the instrument. The principal investigator conducted the data collection personally. A structured questionnaire developed was pre-tested ten days before launching the final data collection on $5 \%$ of the study population in Mizan -Tepi University Mizan campus and required changes was made. The reliability of the data collected was maintained to maximum possible. To ensure the reliability and validity of data the principal investigator put the maximum effort. In this regard experts on the subject matter were contacted and the questionnaire reviewed to obtain the desired variables. The data collected was kept in a lockable cabinet not accessible to anyone other than the principal investigator. In addition the respondents were not allowed to take home the questionnaires so that no references made so that their actual knowledge at the time of the study was analyzed (avoid bias).In addition, each participant was told and strictly followed by the principal investigator to respond to the questions by his/her own, without consulting anyone else, and that all the questions provided in the tool was answered.

\subsection{Data Collection Procedure}

A structured questionnaire developed was pre-tested ten days before launching the final data collection on $5 \%$ of the study population in Mizan-Tepi University and required changes was made. The reliability of the data collected was maintained to maximum possible. To ensure the reliability and validity of data the principal investigator put the maximum effort. In this regard experts on the subject matter were contacted and the questionnaire reviewed to obtain the desired variables. The data collected was kept in a lockable cabinet not accessible to anyone other than the principal investigator. In addition the respondents were not allowed to take home the questionnaires so that no references made so that their actual knowledge at the time of the study was analyzed (avoid bias). In addition, each participant was told and strictly followed by the principal investigator to respond to the questions by his/her own, without consulting anyone else, and that all the questions provided in the tool will be answered. Data was collected by three Public Health under graduate students, using self-administered questionnaires. Students from each collage were being explained about the objective and confidentiality of the study while distributing and collecting the questionnaire.

\subsection{Study Variables}

\subsubsection{Dependent Variable}

- Knowledge, Attitude and practice, risk of premarital sex

\subsubsection{Independent Variable}

- Age, Sex, Socioeconomic status, religion place of living, Ethnicity and Marital status

\subsection{Data Processing, Analysis and Presentation}

Collected data was cleaned, edited, recorded and checked for completeness and consistency and calculated using manual scientific hand calculator. Result is presented by using tables, graph and chart.

\subsection{Operational Definition}

1. Pre-marital sex (PMS) - any sexual intercourse practiced before marriage.

2. Unsafe sex - sex practiced with multiple sexual partner and/or without using condom.

3. Life time sexual partner (LTSP) -the number of sexual partners he/she had since his/her initiation of vaginal intercourse.

4. Knowledge - specific information gained by MizanTepi University, Mizan campus regular students towards premarital sex and HIV/AIDS.

5. Practice- the continuing and repetitive effort of MTU, Mizan campus regular students towards premarital sex and HIV/AIDS.

6. Attitude-behavior of MTU, Mizan campus regular students towards premarital sex and HIV/AIDS.

7. Sexually active students-those students who are active on sexual practice.

8. Coituerche-the age at first sexual intercourse

\subsection{Data Quality Control and Assurance}

The principal investigators were supervised daily for the completeness and consistence of data collected by each data collectors. All materials used for data collection were arranged sequentially. The data was stored in safe and secure place.

\subsection{Ethical Consideration}

Formal letter was written from Mizan-Tepi University, Health Science Collage research program office to distribute 
self-administered questionnaire and conduct the study. The study participants were informed about the objective of the study to obtain desire cooperation, in addition to their willingness the students were requested to give necessary information during data collection. Consent from students was obtained and confidentiality of information obtained was kept strictly and only volunteers were involved.

\section{Results}

\subsection{Socio-Demographic Characteristics}

Among 372(100\%) respondents most of the students $184(49 \%)$ were lie in age group of 22-25 years. Almost more than one third $129(35 \%)$ of the study participants were $3^{\text {rd }}$ years followed by $119(31.7 \%) 1^{\text {st }}$ years, $76(20 \%) 4^{\text {th }}$ years, $37(10 \%) 2^{\text {nd }}$ years and $11(3.3 \%)$ were $5^{\text {th }}$ years students. See table-1 $34.3 \%$ of Nursing students among Health Science students, $25 \%$ of Management students among Business and Economics students, $14.7 \%$ of Animal science among Agricultural and Natural Resource students and 26\% of Psychology students among Social and Humanity students have good awareness about premarital and HIV/AIDS.

Table 1. Socio- demographic characteristics of students by sex, MTU, Mizan, Mizan campus Regular students, 2014.

\begin{tabular}{|c|c|c|c|c|c|c|c|}
\hline \multirow{3}{*}{ Variable } & & \multicolumn{6}{|l|}{ Sex } \\
\hline & & \multicolumn{2}{|c|}{ male } & \multicolumn{2}{|c|}{ female } & \multicolumn{2}{|l|}{ total } \\
\hline & & No & $\%$ & No & $\%$ & No & $\%$ \\
\hline \multirow{5}{*}{ Age in years } & $18-21$ & 122 & $33 \%$ & 42 & $12 \%$ & 164 & $44 \%$ \\
\hline & $22-25$ & 108 & $29 \%$ & 76 & $20 \%$ & 184 & $49 \%$ \\
\hline & $26-30$ & 22 & $6 \%$ & 0 & 0 & 22 & $6 \%$ \\
\hline & 30 above & 2 & $0.5 \%$ & 0 & 0 & 2 & $0.5 \%$ \\
\hline & total & 254 & $68 \%$ & 118 & $32 \%$ & 372 & $100 \%$ \\
\hline \multirow{6}{*}{ religion } & Orthodox & 96 & $26 \%$ & 43 & $12 \%$ & 139 & $38 \%$ \\
\hline & Muslim & 59 & $16 \%$ & 27 & $7 \%$ & 86 & $23 \%$ \\
\hline & Catholic & 31 & $8 \%$ & 9 & $2 \%$ & 40 & $10 \%$ \\
\hline & Protestants & 68 & $18 \%$ & 39 & $10.5 \%$ & 107 & $28.5 \%$ \\
\hline & Others & 0 & 0 & 0 & 0 & 0 & 0 \\
\hline & total & 254 & $68 \%$ & 118 & $32 \%$ & 372 & $100 \%$ \\
\hline \multirow{9}{*}{ Ethnicity } & Oromo & 86 & $18 \%$ & 27 & $7.3 \%$ & 95 & $25.3 \%$ \\
\hline & Amhara & 55 & $15 \%$ & 23 & $6.4 \%$ & 78 & $21.4 \%$ \\
\hline & Tigrie & 32 & $8 \%$ & 14 & $4 \%$ & 46 & $12 \%$ \\
\hline & Somalia & 10 & $3 \%$ & 2 & $0.5 \%$ & 12 & $3.5 \%$ \\
\hline & Gumiz & 14 & $4 \%$ & 3 & $0.8 \%$ & 17 & $4.8 \%$ \\
\hline & Agnuak & 9 & $2 \%$ & 0 & 0 & 9 & $2 \%$ \\
\hline & Afar & 4 & $1 \%$ & 0 & 0 & 4 & $1 \%$ \\
\hline & Others & 62 & $17 \%$ & & 49 & $13 \%$ & 111 \\
\hline & Total & 254 & $68 \%$ & & 118 & $32 \%$ & 372 \\
\hline \multirow{6}{*}{ Collage } & Health Science & 56 & $15 \%$ & 30 & $8 \%$ & 86 & $23 \%$ \\
\hline & Business and Economic & 43 & $12 \%$ & 24 & $6.5 \%$ & 67 & $18.5 \%$ \\
\hline & $\begin{array}{l}\text { Agriculture \&. } \\
\text { Natural .Resources }\end{array}$ & 54 & $14 \%$ & 26 & $7 \%$ & 80 & $21 \%$ \\
\hline & Social \&Humanity & 101 & $27 \%$ & 38 & $10.5 \%$ & 139 & $37.5 \%$ \\
\hline & Total & 254 & $68 \%$ & 118 & $32 \%$ & 372 & $100 \%$ \\
\hline & Health Science & 56 & $15 \%$ & 30 & $8 \%$ & 86 & $23 \%$ \\
\hline \multirow{6}{*}{ Bath } & $1^{\text {st }}$ & 76 & $20 \%$ & 43 & $11.7 \%$ & 119 & $31.7 \%$ \\
\hline & $2^{\text {nd }}$ & 25 & $7 \%$ & 12 & $3 \%$ & 37 & $10 \%$ \\
\hline & $3^{\text {rd }}$ & 89 & $24 \%$ & 40 & $11 \%$ & 129 & $35 \%$ \\
\hline & $4^{\text {th }}$ & 54 & $14 \%$ & 22 & $6 \%$ & 76 & $20 \%$ \\
\hline & $5^{\text {th }}$ & 10 & $3 \%$ & 1 & $0.3 \%$ & 11 & $3.3 \%$ \\
\hline & total & 254 & $68 \%$ & 118 & $32 \%$ & 372 & $100 \%$ \\
\hline
\end{tabular}

Among study participants majority 333(89\%), of them were single followed by married 39(10.9\%). From study participants most of their family were illiterate $189(51.6 \%)$, followed by $1-8101(27 \%), 9-1244(11.5 \%)$ and more than $1238(9.9 \%)$ respectively.

Table 2. Routes of HIV transmission known by different collage of MTU, Mizan campus regular students /2014.

\begin{tabular}{|c|c|c|c|c|c|c|c|}
\hline \multirow{2}{*}{ variable } & & & \multicolumn{5}{|c|}{ Major routes HIV transmission } \\
\hline & & & sexual & Unsafe use of sharp object & Blood transfusion & Mother to child & total \\
\hline \multirow{6}{*}{ Collage } & \multicolumn{2}{|c|}{ Health science } & 65 & 8 & 9 & 4 & 86 \\
\hline & \multicolumn{2}{|c|}{ Business and Economics } & 52 & 6 & 4 & 5 & 67 \\
\hline & \multicolumn{2}{|c|}{ Social and Humanity } & 110 & 18 & 6 & 5 & 139 \\
\hline & \multicolumn{2}{|c|}{ Agriculture and N. Resources } & 54 & 15 & 5 & 6 & 80 \\
\hline & \multirow{2}{*}{ total } & No & 281 & 47 & 24 & 20 & 372 \\
\hline & & $\%$ & $75.5 \%$ & $12.6 \%$ & $6.45 \%$ & $5.35 \%$ & $100 \%$ \\
\hline
\end{tabular}




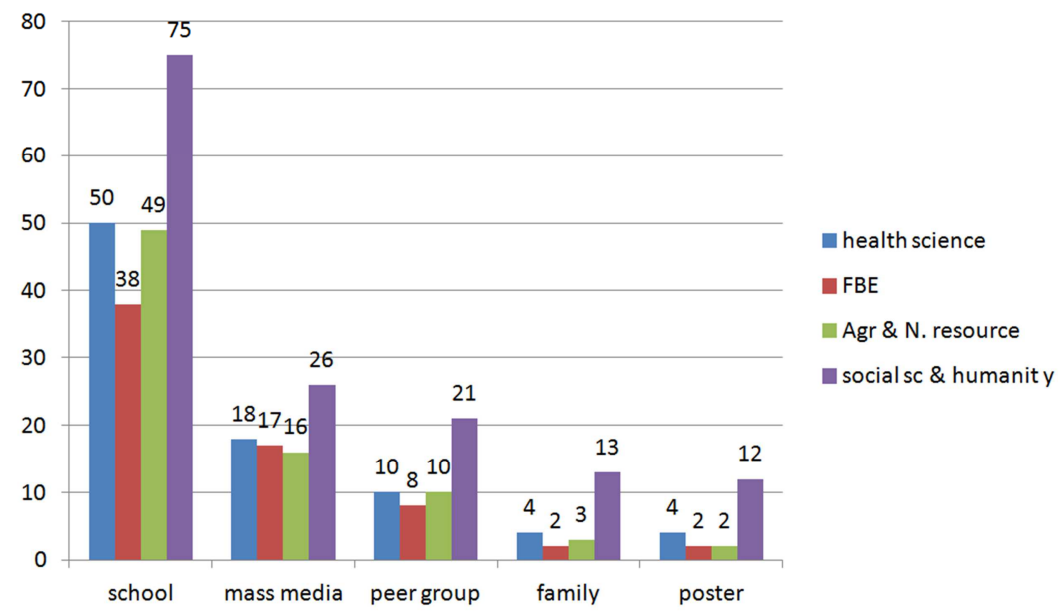

Fig. 1. Source of information about HIV/AIDS by students of different collage MTU Mizan campus regular students /2014.

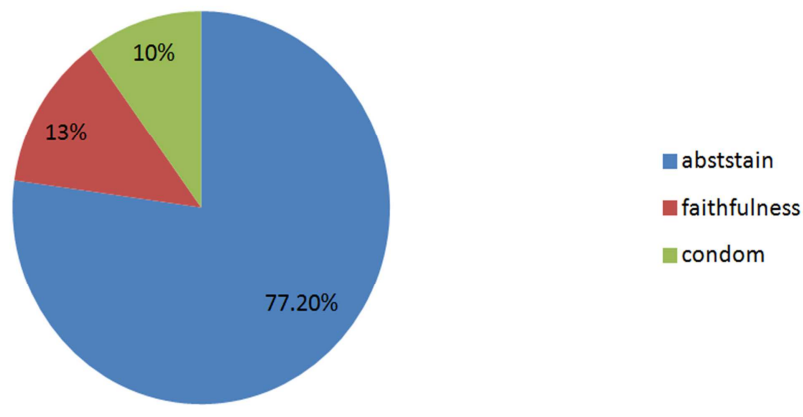

Fig. 2. Know preferred method of protection against HIV/AIDS by sexual active students of MTU, Mizan campus regular students /2014.

Among 372 participants majority of the students known that premarital sex lead to vulnerable to HIV/AIDS and STD $227(61 \%)$, unwanted pregnancy $85(22.8)$, unsafe abortion and its complications $41(11 \%)$ and dropout from education $19(5.2 \%)$. Therefore, the major health problems of premarital sex were vulnerable to HIV/AIDS and STI 227(61\%).

Table 3. Attitude towards premarital sex-by-sex MTU, Mizan campus regular students /2014.

\begin{tabular}{|c|c|c|c|c|c|c|}
\hline \multirow{3}{*}{ Attitude } & \multicolumn{6}{|l|}{ sex } \\
\hline & \multicolumn{2}{|c|}{ Male } & \multicolumn{2}{|l|}{ Female } & \multicolumn{2}{|c|}{ Total } \\
\hline & No & $\%$ & No & $\%$ & No & $\%$ \\
\hline Agree & 70 & $18.8 \%$ & 16 & $4.3 \%$ & 86 & $23.1 \%$ \\
\hline Disagree & 140 & $37.4 \%$ & 93 & $25 \%$ & 233 & $62.4 \%$ \\
\hline Neutral & 44 & $14.8 \%$ & 9 & $2.4 \%$ & 53 & $14.2 \%$ \\
\hline Total & 254 & $68 \%$ & 118 & $32 \%$ & 372 & $100 \%$ \\
\hline
\end{tabular}

Table 4. Attitudes towards premarital sex by religion and collage, MTU, Mizan campus regular students /2014.

\begin{tabular}{|c|c|c|c|c|c|c|c|c|c|}
\hline \multirow{3}{*}{ Variable } & & \multicolumn{8}{|c|}{ Attitude towards premarital sex } \\
\hline & & \multicolumn{2}{|c|}{ Agree } & \multicolumn{2}{|c|}{ Disagree } & \multicolumn{2}{|c|}{ Neutral } & \multicolumn{2}{|c|}{ Total } \\
\hline & & No & $\%$ & No & $\%$ & No & $\%$ & No & $\%$ \\
\hline \multirow{5}{*}{ Religion } & Orthodox & 60 & $16 \%$ & 56 & $15 \%$ & 23 & $6.5 \%$ & 139 & $37.5 \%$ \\
\hline & Protestants & 79 & $21 \%$ & 17 & $4.5 \%$ & 11 & $3 \%$ & 107 & $28.5 \%$ \\
\hline & Muslim & 20 & $5.4 \%$ & 56 & $15 \%$ & 10 & $3 \%$ & 86 & $23.4 \%$ \\
\hline & Catholic & 21 & $5.6 \%$ & 12 & $3.5 \%$ & 7 & $2 \%$ & 40 & $10.6 \%$ \\
\hline & Total & 180 & $48 \%$ & 141 & $37.5 \%$ & 51 & $14.5 \%$ & 372 & $100 \%$ \\
\hline \multirow{5}{*}{ Collage } & Health Science & 43 & $11.5 \%$ & 33 & $8.9 \%$ & 10 & $2.6 \%$ & 86 & $23 \%$ \\
\hline & Business and Economics & 28 & $7.5 \%$ & 27 & $7 \%$ & 12 & $3.2 \%$ & 67 & $17.6 \%$ \\
\hline & Agricultural and Natural Resource & 30 & $8 \%$ & 33 & $8.9 \%$ & 17 & $4.5 \%$ & 80 & $21.4 \%$ \\
\hline & Social and Humanity & 37 & $10 \%$ & 82 & $22 \%$ & 20 & $5.4 \%$ & 139 & $42.4 \%$ \\
\hline & Total & 138 & $37 \%$ & 175 & $46.8 \%$ & 59 & $15.7 \%$ & 372 & $100 \&$ \\
\hline
\end{tabular}


Table 5. Sexual practices of students by sex, age, collage, batch and religion MTU students, Mizan campus regular students /2014.

\begin{tabular}{|c|c|c|c|c|c|c|c|}
\hline \multirow{3}{*}{ variable } & & \multicolumn{6}{|c|}{ Sexual practice } \\
\hline & & \multicolumn{2}{|c|}{ Yes } & \multicolumn{2}{|l|}{ No } & \multicolumn{2}{|c|}{ Total } \\
\hline & & No & $\%$ & No & $\%$ & No & $\%$ \\
\hline \multirow{3}{*}{ Sex } & Male & 112 & $30 \%$ & 142 & $38 \%$ & 254 & $68 \%$ \\
\hline & Female & 21 & $5.6 \%$ & 97 & $26 \%$ & 118 & $32 \%$ \\
\hline & total & 133 & $35.6 \%$ & 239 & $64.4 \%$ & 372 & $100 \%$ \\
\hline \multirow{5}{*}{ Age } & $18-21$ & 39 & $10.4 \%$ & 125 & $33.6 \%$ & 164 & $44 \%$ \\
\hline & $22-25$ & 86 & $23.1 \%$ & 98 & $254.9 \%$ & 184 & $49 \%$ \\
\hline & $26-29$ & 7 & $1.85 \%$ & 15 & $4.8 \%$ & 22 & $6.6 \%$ \\
\hline & 30 and above & 1 & $0.2 \%$ & 1 & $0.2 \%$ & 2 & $0.45 \%$ \\
\hline & Total & 133 & $35.7 \%$ & 239 & $44.3 \%$ & 372 & $100 \%$ \\
\hline \multirow{5}{*}{ Religion } & Orthodox & 52 & $14 \%$ & 87 & $24 \%$ & 139 & $38 \%$ \\
\hline & Protestants & 44 & $12 \%$ & 63 & $16.5 \%$ & 107 & $28.5 \%$ \\
\hline & Muslim & 26 & $7 \%$ & 60 & $16 \%$ & 86 & $23 \%$ \\
\hline & Catholic & 11 & $3 \%$ & 29 & $7.5 \%$ & 40 & $10.5 \%$ \\
\hline & Total & 133 & $35.6 \%$ & 239 & $64.4 \%$ & 372 & $100 \%$ \\
\hline \multirow{5}{*}{ Collage } & Health Science & 34 & $9 \%$ & 52 & $14 \%$ & 86 & $23 \%$ \\
\hline & Business and Economics & 23 & $6.2 \%$ & 44 & $12.3 \%$ & 67 & $18.5 \%$ \\
\hline & Agricultural and Nat. Resource & 29 & $7.8 \%$ & 51 & $13.2 \%$ & 80 & $21 \%$ \\
\hline & Social and Humanity & 47 & $12.6 \%$ & 92 & $24.9 \%$ & 139 & $37.5 \%$ \\
\hline & Total & 133 & $35.6 \%$ & 239 & $64.4 \%$ & 372 & $100 \%$ \\
\hline \multirow{6}{*}{ Batch } & $1^{\text {st }}$ & 43 & $11.5 \%$ & 76 & $20.2 \%$ & 119 & $31.7 \%$ \\
\hline & $2^{\text {nd }}$ & 12 & $3.2 \%$ & 25 & $6.8 \%$ & 37 & $10 \%$ \\
\hline & $3^{\text {rd }}$ & 52 & $14 \%$ & 77 & 215 & 129 & $35 \%$ \\
\hline & $4^{\text {th }}$ & 21 & $5.6 \%$ & 55 & $14.4 \%$ & 76 & $20 \%$ \\
\hline & $5^{\text {th }}$ & 5 & $1.3 \%$ & 6 & $2 \%$ & 11 & $3.3 \%$ \\
\hline & Total & 133 & $35.6 \%$ & 239 & $64.4 \%$ & 372 & $100 \%$ \\
\hline
\end{tabular}

Most of the students $133(35.6 \%)$ had their first sexual intercourse between the age 22-25 years. The earliest coitus reported was at the age 15-16.5 years for female and 16-18 years for male.

Regarding number of lifelong sexual partner(s) among participants who were practice sex $220(59.2 \%)$ of students had a single partner, $124(33.3 \%)$ of students had two partners, $11(7.4 \%)$ of students had three and above and the remaining had no partner.

Commercial sex worker were sexual partners for 4 (3.7\%), other categories and as sexual partners for the study students were government employees 16(14\%), students 76(70.4\%) and merchants $12(11.1 \%)$. 98(16.5\%) students of the total study subjects had sexual intercourse in the last 3 months. Among reason given for not used condom the highest was partner trust that account $35(9.4 \%)$.

Table 6. Reason given for premarital sex in their who agreed premarital sex by sex, MTU, Mizan campus students /2014.

\begin{tabular}{|c|c|c|c|c|c|c|}
\hline \multirow{3}{*}{ Reasons } & \multicolumn{6}{|l|}{ Sex } \\
\hline & \multicolumn{2}{|c|}{ male } & \multicolumn{2}{|c|}{ female } & \multicolumn{2}{|c|}{ Total } \\
\hline & No & $\%$ & No & $\%$ & No & $\%$ \\
\hline Physical attraction & 133 & $35.7 \%$ & 78 & $21 \%$ & 211 & $56.7 \%$ \\
\hline For pleasure & 24 & $6.5 \%$ & 6 & $1.7 \%$ & 30 & $8 \%$ \\
\hline peer influence & 83 & $22 \%$ & 23 & $6.3 \%$ & 106 & $28.5 \%$ \\
\hline As mean of income & 0 & 0 & 11 & $3 \%$ & 11 & $3 \%$ \\
\hline $\begin{array}{l}\text { Alcohol and } \\
\text { substance abuse }\end{array}$ & 14 & $3.8 \%$ & 0 & 0 & 14 & $3.8 \%$ \\
\hline Total & 254 & $68 \%$ & 118 & $32 \%$ & 372 & $100 \%$ \\
\hline
\end{tabular}

\section{Discussion}

Globally the number of people living with HIV/AIDS continues to grow, as does the number of deaths from HIV/AIDS. According to UNAIDS report, a total number of 33.2 million people were living with HIV in 2010. This figure including the estimated 2.1 million adults and 42,000 children who were newly infected with HIV/AIDS in 2010, there were 2.1 million deaths because of HIV/AIDS in the year 2010. Sub-Saharan African sentiment to bear the burden of the global epidemic. A total 22.5 million (67.7\%) of the people were living with HIV in 2010 in the SubSaharan Africa and adult prevalence of 5\% is reported (4).

According to the 2000 Ethiopia demographic health survey among currently unmarried individuals, 29\% have had sexual intercourse with more than one partners which showed that multiple sexual contact among unmarried person is common especially among aged 20 and above which is similar with our study $135(40.7 \%)$; had multiple sexual partners among age group 22-25 year(13).Having the above information as a background, this study has attempted to assess attitude towards premarital sex and reasons given against condom use and we tried to assess the knowledge about HIV/AIDS, its route of transmission and protective measures against HIV/AIDS in MTU, Mizan campus, regular students. There was a high degree of knowledge about HIV/AIDS, its mode of transmission among our study subjects in which all of the students heard 
about HIV/AIDS and know the mode of transmission routes which is similar with the study done in Jimma University in 2002, $(4,21 \%)(21)$. The most important source of information mentioned was school, which is in contrast to findings in high school students, Jimma University (21) and Addis Ababa University students(6). 35.6\% approved premarital sex, which is almost similar with study done in Nekemte in 2008 which showed that 145(21.55\%) adolescents reported premarital sexual intercourse (20).

Most of the students had single sexual partner that is similar to Assefa's report (16). This again showed that the knowledge of the students about the disease is far from practice and put them in a high-risk situation (20).Regarding to condom use $98(26 \%)$ of the sexual active students use it, which is higher than Engida's report (21). This could be due to their high level of education and easy availability of condom. Partner trust that accounts $35(9.4 \%)$ was the commonest reason given for not to use condom as was cited in Engida's report (21). Though faithfulness is an important way of protection, it has definitely a high risk before marriage. The majority of the students knew the $\mathrm{ABC}$ of protection against HIV/AIDS and the preferred method mentioned was Abstinence 287(77.2\%)although it was not seen in practice as $133(35.6 \%)$ of them engaged in sexual activity which is similar to Ismail's research(11) done in University of Gondar. The age interval at which the first coitus in our study was 15-16.5 years for females and 16-18.5 years for males which was greater than Assefa's and Dessalegn's report(13.3-16 for females and 16-18 years for males) (16).Among the study participants $59.2 \%$ of the students were single that was less than Kidane report ( $61.4 \%$ were single) (14).

\section{Strength and Weakness of the Study}

The study is interesting in which authors explored Knowledge Attitude and Practice towards premarital sex and HIV/AIDS among Mizan-Tepi University students, south west Ethiopia, less explored in previous studies. However, the relatively small sample size and the single center study limit the generalizability of the study findings.

\subsection{Strength of the Study}

- The data was collected using a structured selfadministered pre-tested questionnaire

- Adequate sample size was applied according to single population proportion formula

- Data collators were health professional

\subsection{Weakness of the Study}

- During this study there may be observational bias

- There were financial constraint while conducting the Study

- All respondents were interviewed but some of them observed during the study period

Some of the respondents were volunteer during data collection.

\section{Conclusion}

The study participants have good knowledge and attitude about premarital sex and HIV/AIDS, its cause, the routes of transmission and above the preventive mechanism, but this knowledge not practiced among the study participants. The contribution of family and poster as a source of information was seen to be less revealing the premarital sex and HIV/AIDS agenda among these groups. The study participants were citing religion as a reason for not having premarital sex and this should be included in their day-to-day teachings. Even if there were high incidence of single sexual partnerships which may put the study participants at a high risk to HIV/AIDS if no faithfulness between them.

\section{Author's Contributions}

ZM, have made substantial contributions to beginning and design, collection of data, analysis and interpretation of data and in drafting the manuscripts and correcting the comment given by the advisors.

EW involved in revising the research paper and the manuscript critically for important intellectual context and approval of the final version to be published and participated in its design and coordination. He participated in the approval and funding process, participated in the design of the study participated in its design and coordination.

EA, involved in revising the research paper and the manuscript critically for important intellectual context and approval of the final version to be published and participated in its design and coordination.

AAG had greater contribution in reviewing the manuscript English and topography. And helped to draft the manuscript.

\section{Acknowledgement}

We are thankful to all our department technical staffs for their excellent technical support.We are grateful to all the participants for their cooperation and Tepi Mizan University for financial support.

\section{References}

[1] Zerai Kassaye, Z (2005).Sexual experience and their correlates amongJU students Jimma Ethiopia. Heal Sci; 15(1): $1-17$.

[2] Zelalem Fekadu, casual sex -debuts among female students in Addis Ababa, Ethiopia, J. health Dev, 2001; 15(2): 109-116.

[3] Fikadu A., Fikadu K(2000).. Creating a better future for Ethiopian youth. A conference on A and H. THE O and vid and (Luel) packord foundation. Bahir dar, Ethiopia Nov 6-9, 2000 .

[4] Fisseha Eshetu, attitudes of students, parents and teachers towards the promotion of condom for adolescents Eth. J, Heal. Dev, 1999; 11(1): 17-22, 2001.

[5] Federal MOH of Ethiopia. December 20011; 1-2. 
[6] Anteneh Korra, Mesfine Haile, sexual behavior and level of awareness on reproductive health among youths, Evidence from Harara Eastern Ethiopia, Ethiopia J. heal Dev, 1999, 13(2); 107-113.

[7] Harrison, Harrison principle of internal medicines $16^{\text {th }} \mathrm{Ed}$.

[8] UNAIDS, WHO, AIDS epidemic update, Dec 2004, 19-26.

[9] Tffy N. Do young people and parents communicate on sexual matter? Eth. J, Heal. Dev, 1995 12(2); 152-156.

[10] Gage, A.S and Meeker, D. sexual activity before marriage in Sub-Saharan Africa, Soc, B.O; 1993, 14-60.

[11] Ismail's, high risk behavior for STD/AIDS pregnancies and contraception among high school students in rural town, North West Ethiopia, Eth. J. Heal. Dev, 1997; 11(1) : 29-36.

[12] Central Statistical Authority, Ethiopia Demographic health survey 2000, central statistical authority A.A, 1996; 10(1): 3539.

[13] G. Alene, J, Whelee and H. Gross Hurth. A adolescent reproductive health and awareness of HIV among rural high school students, North Western Ethiopia, AIDS care 16(1); 57 68 .

[14] Kidane G/Kidane, survey of condom use among college students Eth. J. Heal. Dev. 1995; 9(1); 7-11.

[15] $\mathrm{MOH}, 2000$, AIDS in Ethiopia, $\mathrm{MOH}$.
[16] Assefa S. and DessalegnW(2008). premarital sexual practice among school adolescents in high education level in Et. J, Health: 22(2).

[17] Mulu, W., Abera, B., Mulat Yimer,M(2014). Knowledge, Attitude and Practices on HIV/AIDS among Students of Bahir Dar University. Science Journal of Public Health. 2( 2): 78-86. doi: $10.11648 /$ j.sjph.20140202.16

[18] Nyarko, K., Adentwi, KI., Asumeng, M., Ahulu,LD(2014). Parental Attitude towards Sex Education at the Lower Primary in Ghana. International Journal of Elementary Education. 3(2): 21-29. doi: 10.11648/j.ijeedu.20140302.11

[19] Horn of Africa, journal of AIDS, 2006; 1(11); 36.

[20] Ahmed Abdulla, Reproductive study an abortion, Eth. J, Heal. Dec, 1996; 10(3); 167-170.

[21] Federal ministry of health five year action plan document for adolescent RH in Ethiopia family health Department, Addis Ababa, 2001.

[22] Assefa S., Dessalegn W. premarital sexual practice among school adolescents in Nekemte town, East Wolllega Ethiopia. J, Health Dev, 2008; 22(2).

[23] Enngida Abebe, attitude and practice of premarital sex and knowledge of its risk as pre disposing to HIV/AIDS among JU students-2002, Jimma Ethiopia. 